\title{
A Novel QbD Based SPE-HPLC Bio-analytical Method for Edaravone in Rat Plasma, A Pharmacokinetic Study
}

\author{
Suraj Fanse', Madhuri Baghel', Prachi Bhamre', Sadhana Rajput ${ }^{1 *}$ \\ ${ }^{1}$ Quality Assurance Laboratory, Centre of Relevance and Excellence in Novel Drug Delivery System, Pharmacy Department, G. H. Patel \\ Building, Donor's Plaza, The Maharaja Sayajirao University of Baroda, Fatehgunj, Vadodara, Gujarat, INDIA.
}

\begin{abstract}
A simple, sensitive and feasible Quality by design based RP-HPLC bioanalytical method was developed and validated for Edaravone. Plackett burman design and $3 \square 3$ full factorial designs were utilized for factor screening and optimization respectively, to achieve well resolved asymmetric peaks of both internal standard and drug with good theoretical plates. The optimized chromatographic peak was obtained with mobile phase composition of $10 \mathrm{mM}$ ammonium acetate buffer $(\mathrm{pH} \mathrm{6)}$ and acetonitrile $(60: 40, \mathrm{v} / \mathrm{v})$ at a flow rate of $1.0 \mathrm{ml} / \mathrm{m}$ and detection wavelength of $243 \mathrm{~nm}$ using Kromasil $\mathrm{C}_{18}(250 \mathrm{~mm} \times 4.6 \mathrm{~mm}$; $5 \mu \mathrm{m})$ column. Non normality, skewness or outliers did not exist as demonstrated by residual plot. To eliminate the possible interferences in the biological matrices, a new solid-phase extraction method using STRATA $X_{C_{18}}$ Phenomenex cartridges was developed and evaluated. The method was validated as per USFDA guideline. The developed method was efficiently applied to pharmacokinetic study in rat plasma.
\end{abstract}

Keywords: QbD, SPE, Bioanalytical method, Edaravone, Carbamazepine.

\section{INTRODUCTION}

Edaravone (EDA) is a neurotrophic drug used in treatment of acute ischemic stroke and myocardial infarction. It acts as a free radical scavenger, lowers lipid-peroxidation induced neuronal death and subsequent oxidative stress of endothelial cells of brain, thereby reducing cerebral edema and cerebral infarction. ${ }^{1}$ Chemically, EDA is 5-methyl2-phenyl-2, 4-dihydro-3H-pyrazol-3-one. It is not official in any of the pharmacopoeias. Carbamazepine (CAR), which is 5H-dibenzo [b, f] azepine-5-carboxamide, is used as internal standard in the present study.

Literature review revealed that some methods have been reported for Edaravone individually and in combination. Fluorescent assay, ${ }^{3}$ derivative UV spectrophotometric RPHPLC method for combination of Edaravone and
Citicoline, ${ }^{4,5}$ HPLC method for determination of phenyl hydrazine residues in $\mathrm{EDA}^{6}$ have been reported. HPTLC method for estimation of Edaravone in human plasma ${ }^{2}$ has been described. Liquid liquid extraction (LLE) was used to isolate edaravone from biological matrix followed by spotting of the extracts onto a Pre coated RP-18 $\mathrm{F}_{254}$ aluminum sheet. Rf value of EDA was found to be $0.81 \pm 0.01$. The LOD and LOQ were $25 \mathrm{ng} / \mathrm{spot}$ and $150 \mathrm{ng} / \mathrm{spot}$ respectively. Also LC-MS/MS method for estimation of Edaravone and Taurine in rat plasma ${ }^{7}$ has been stated. In this method 3-methyl-1p-tolyl-5-pyrazolone and sulfanilic acid were used as internal standards (IS) for simultaneous or independent determination of taurine and edaravone in rat plasma. Chromatographic separations were achieved
Submission Date : 07-04-2016 Revision Date : 09-06-2016 Accepted Date : 11-06-2016

DOI: 10.5530/ijper.50.4.8

Correspondence:

Sadhana Rajput,

Professor, Quality

Assurance laboratory,

Centre of Relevance and

Excellence in Novel Drug

Delivery Systems, Pharmacy

Department, G.H. Patel

Building, The Maharaja

Sayajirao University of Baroda, Fatehgunj, Vadodara, Gujarat, INDIA.

E-mail: sjrajput@gmail.com

Phone no:

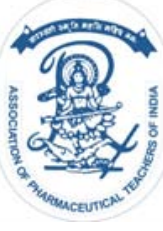

www.ijper.org 
on an Agilent Zorbax SB-Aq $(100 \square 2.1 \mathrm{~mm}, 3.5 \mu \mathrm{m})$ column using mobile phase Gradient $0.03 \%$ formic acid-methanol, isocratic $0.1 \%$ formic acid-methanol (90:10) and 0.02\% formic acid-methanol (40:60). On thorough literature search no report has been found relating to SPE- HPLC bioanalytical method using systematic QBD approach. Hence, the present work aims to develop a simple RP-HPLC bioanalytical method for estimation of EDA in human plasma employing a novel QBD approach that could be successfully employed for analysis of rat plasma samples following intravenous administration.

\section{EXPERIMENTAL}

\section{Instrumentation and software}

Chromatography was performed on Shimadzu (Shimadzu Corporation, Kyoto, Japan) chromatographic system equipped with Shimadzu LC-20AT pump and Shimadzu SPD-20AV absorbance detector. Samples were injected through a Rheodyne 7725 injector valve with fixed loop at $20 \mu \mathrm{l}$. Data acquisition and integration was performed using Spinchrome software (Spinco biotech, Vadodara). Ezypress HT48 (OROCHEM) solid phase extractor and STRATA $\mathrm{X} \mathrm{C}_{18}$ cartridges (PHENOMENEX) were used for solid phase extraction. Minitab 17 software was used for Plackett Burman design (PBD), and Statease Design expert v.9.0 was employed for optimization stage in QBD. Thermo Kinetica PK/PD analysis software (version 5.0 Thermo Fisher Scientific) was used for pharmacokinetic modeling.

\section{Reagents and Chemicals}

Drug samples of EDA (99.7\% purity) and CAR (99.9\% purity) were obtained as gift samples from BDR Pharmaceutical International Pvt. Ltd. Vadodara and Sun Pharmaceuticals, Vadodara respectively. Methanol and acetonitrile (ACN) (HPLC grade, Spectrochem), glacial acetic acid (HPLC grade, Merck), ammonium acetate (HPLC grade, Rankem) and double distilled water were used for the analysis. All the aqueous solutions for analysis were filtered through $0.2 \mu \mathrm{m}$ nylon membrane filter paper (Pall Lifesciences, Mumbai, India).

\section{Chromatographic condition}

Separation and quantitation were performed on Kromasil $\mathrm{C}_{18}$ column $(250 \mathrm{~mm} \times 4.6 \mathrm{~mm} ; 5 \mu \mathrm{m})$. The mobile phase comprised of ammonium acetate buffer, $\mathrm{pH} 6$ adjusted with glacial acetic acid: ACN in ratio of 60:40 at a flow rate of $1.0 \mathrm{ml} / \mathrm{min}$ at ambient temperature. Detection was carried out at wavelength of $243 \mathrm{~nm}$.

\section{Preparation of Standard Solutions}

A standard solution $(1 \mathrm{mg} / \mathrm{ml})$ of EDA was prepared in ACN. This solution was used for preparing the plasma samples by withdrawing appropriate aliquots. A standard solution $(1 \mathrm{mg} / \mathrm{ml})$ of internal standard, CAR was prepared in ACN. From this, the working internal standard (IS) spiking solution $(400 \mu \mathrm{g} / \mathrm{ml})$, was prepared by appropriate dilution in ACN.

\section{Preparation of calibration standards and quality control (QC) samples}

Spiking solutions of EDA were prepared in ACN using appropriate volumes of above standard solution to make calibration curve standards in the range of 500 to 20,000 $\mathrm{ng} / \mathrm{ml}$. QC samples were independently prepared by spiking drug-free plasma with appropriate amounts of EDA to give concentrations corresponding to $500 \mathrm{ng} / \mathrm{ml}$ (LLOQ QC), $800 \mathrm{ng} / \mathrm{ml}$ (LQC), $7500 \mathrm{ng} / \mathrm{ml}$ (MQC) and $15,000 \mathrm{ng} / \mathrm{ml}$ (HQC) levels of the calibration curve.

\section{Plasma Sample preparations}

EDA and CAR (IS) were extracted from plasma using solid phase extraction (SPE) method. To each aliquot $(1.8 \mathrm{ml})$ of plasma (calibration standards, QC samples or rat samples), $0.1 \mathrm{ml}$ of spiking solutions of EDA and $0.1 \mathrm{ml}, 400 \mu \mathrm{g} / \mathrm{ml}$ of IS solution was added. STRATA $\mathrm{X} \mathrm{C}_{18}$ Phenomenex cartridges were used for SPE. Sample pre-treatment was carried out by taking $0.5 \mathrm{ml}$ of plasma sample and adding $0.5 \mathrm{ml}$ water to it (sample dilution 1:2). The cartridges were conditioned with 0.5 $\mathrm{ml}$ methanol and equilibrated with $0.5 \mathrm{ml}$ water. Then $0.5 \mathrm{ml}$ of pre-treated sample were loaded onto the cartridges. The cartridges were rinsed with $0.5 \mathrm{ml}$ water to wash the interferents and elution of analytes was carried out with $0.5 \mathrm{ml}$ mixture of $\mathrm{ACN}$ : ammonium acetate buffer $\mathrm{pH} 6$ in the ratio of 80:20. The eluent was further dried with nitrogen purging for 1-2 $\mathrm{m}$ and thereafter the volume of dried residue was reconstituted with ACN and injected into HPLC ( $20 \mu$ linjection volume).

\section{Bioanalytical Method validation}

Method validation was carried out according to the USA Food and Drug Administration (USFDA) Bioanalytical method validation guidelines. ${ }^{8}$

Selectivity: Selectivity of the assay method was assessed by evaluating potential interference from endogenous compounds in the plasma using six plasma samples under the optimized chromatographic conditions. Blank (without IS) and zero standard sample (with IS and without EDA) were analysed. These samples were compared with standard plasma samples spiked with EDA in order to evaluate interference of plasma at the retention 
times of EDA or IS. The selectivity of the method has beenshown in Figure 4 which consists of the chromatogram of blank human plasma, zero standard and extracted sample.

Limit of detection (LOD) and lower limit of quantification (LLOQ): In order to estimate the LOD and LLOQ, drug-free plasma sample was extracted and six replicates were injected and analysed according to the optimized chromatographic conditions. Similarly plasma samples spiked with drug were injected.

Linearity of calibration curves: The linearity of the method was determined over calibration range of 500$20,000 \mathrm{ng} / \mathrm{ml}$. To a plasma sample aliquot $(1.8 \mathrm{ml})$ of each calibration standard, $0.1 \mathrm{ml}(400 \mu \mathrm{g} / \mathrm{ml})$ IS was added. The calibration standards were prepared by spiking known concentration of EDA working standard solutions. A linearity curve containing seven non-zero concentrations was analysed. Concentrations of each level were plotted against the area ratio of drug to IS. Back calculated concentration of each calibration standard, slope, $y$-intercept and correlation coefficient of the curve were calculated by suitable linear regression analysis.

Precision and accuracy: Precision and Accuracy of the method were determined by replicate analysis of five determinations at four concentration levels which covers the calibration range: LLOQ, LQC, MQC, and HQC. These QC samples were analyzed against the calibration curve and obtained concentrations compared with the nominal value. Precision is expressed as the \% coefficient of variation (\% CV). The accuracy and precision were evaluated as within batch (intraday, replicate analysis on same day) and between-batch (interday, replicate analysis for three consecutive days).

Extraction recovery: The extraction recovery of EDA and CAR in plasma was evaluated by comparing the mean peak responses of five replicate injections of each LQC, MQC and HQC sample (prepared in plasma), to the mean peak responses of aqueous unextracted samples (without plasma). Also, the recovery of the IS was simultaneously evaluated. Percentage recovery was found as:

$\%$ Recovery $=[$ peak area of EDA concentration extracted from spiked plasma/ peak area of EDA concentration without plasma) $\times 100]$.

Matrix Factor: Matrix factor is investigated to check the effect of plasma matrix from different sources or population on the response of drug and IS. Matrix factor was calculated using 3 different lots of plasma samples. For each analyte and the IS, the matrix factor (MF) should be calculated for each lot of matrix, by calculating the ratio of the peak area in the presence of matrix (measured by analyzing blank matrix spiked after extraction with analyte), to the peak area in absence of matrix (pure solution of the analyte). The IS normalized MF was also calculated by dividing the MF of the analyte by the MF of the IS. This determination was carried out at LQC and HQC.

Dilution Integrity: Dilution integrity was evaluated at dilution range of 1:2 and 1:4 respectively. A dilution integrity standard of $40 \mu \mathrm{g} / \mathrm{ml}$ (a concentration twice that of ULOQ) was prepared and frozen for a period of at least 24 hours. On the day of evaluation, the dilution integrity standard could be diluted for 3 replicates each by a factor of 2 times and 4 times using the prescreened blank plasma. Dilution integrity samples were processed and analyzed against a freshly prepared calibration curve.

Stability: According to the guidelines, stability studies of samples were performed at LQC and HQC levels. For bench top stability, three replicates of LQC and HQC samples in plasma were kept at room temperature for $24 \mathrm{hrs}$ (referred to as stability samples). After $24 \mathrm{hrs,}$ fresh samples were prepared in three replicates (referred to as fresh or comparison samples) with respect to which the stability QC samples were analyzed. The freeze thaw (FT) stability of analyte was determined after three FT cycles. 3 sets of LQC and HQC are stored at $-5^{\circ} \mathrm{C}$ to $-20^{\circ} \mathrm{C} \pm 5^{\circ} \mathrm{C}$ for $24 \mathrm{hrs}$. These were thawed unassisted at room temperature. Likewise, two more such FT cycles were repeated. All the stability samples were analyzed and compared with freshly prepared QC samples and back-calculated against freshly prepared calibration curve.

The room temperature (short term) stock solution stability of EDA and CAR was determined at room temperature for $24 \mathrm{hrs}$. Room temperature stock solution stability was performed by analyzing three replicates of aqueous solutions prepared from freshly prepared stock solution against three replicates of aqueous solution prepared from aliquots of analyte and IS stored at room temperature for $24 \mathrm{hrs}$ (stability samples). The refrigerated (long term) stock solution stability of EDA and CAR were determined at $2-8^{\circ} \mathrm{C}$ after 7 days. Refrigerated stock solution stability was performed by analyzing three replicates of aqueous solution prepared from freshly prepared stock solution against three replicates of aqueous solution prepared from aliquots of analyte and IS stored at $2-8^{\circ} \mathrm{C}$ after 7 days (1 week).

Application of the proposed method: The validated HPLC method was applied to investigate the pharmacokinetic study of EDA in rats. The pharmacokinetic study was carried out in Male Sprague Dawley rats. Six healthy animals weighing 200-250 gm were selected for the 
study. The animals were fasted overnight $(\sim 14 \mathrm{~h})$ and had free access to water throughout the experimental period. EDA was administered by intravenous route via tail vein at a dose of $1 \mathrm{mg} / \mathrm{kg}$, as an aqueous solution. Blood samples $(0.3 \mathrm{ml})$ were collected from the retroorbital plexus sinus at designated time points $(5,10$, $15,20,30$ and $40 \mathrm{~m}$ ) into micro centrifuge tubes each containing $50 \mu \mathrm{l}$ of EDTA. Plasma was harvested by centrifuging the blood using cold centrifuge at 4000 rpm for $10 \mathrm{~m}$. Plasma (200 $\mu \mathrm{l})$ samples were spiked with IS and processed same as standards as described above.

\section{RESULTS AND DISCUSSIONS}

\section{QbD approach to bioanalytical method development and optimization ${ }^{9,10}$ :}

Preliminary investigations: The Ishikawa cause and effect diagram (Figure 1) depicting various factors i. e. CPP's (Critical Process Parameters) and their influences on the CQA's (Critical Quality Attributes) were studied. Effects like $\mathrm{pH}$, temperature, flow rate, Buffer ratio and strength of buffer, volume of sample injected, etc had been studied.

Selection of stationary phase: Various chromatographic trials were performed on different columns like Kromasil C 18 (250 $\square 4.6 \mathrm{~mm})$, Oyster $\mathrm{C}_{8}(250 \square 4.6 \mathrm{~mm})$ and Hypersil $\mathrm{C}_{4}$ column (100 $\square 4.6 \mathrm{~mm}$ ). Best results were obtained using Kromasil $\mathrm{C}_{18}$ column.

PBD for screening of critical variables: 7 factors namely $\mathrm{pH}$, Flow rate, Buffer ratio, Buffer strength, Temperature, Detection wavelength and volume of sample injected which influence the method parameters were investigated for their significance on the analytical method employing a PBD. Five responses were studied, namely Retention time of EDA, Resolution, Symmetry factor, Theoretical plates and Area of EDA. Table 2 summarizes the Factorial fit for the model developed.

Pareto charts as shown in Figure 2 explain the degree of effect of each CPP's on CQA's in the form of bars. This begins with the most significant response followed by other responses in decreasing order of their contribution to the corresponding factor.

The difference between observed response and fitted response value is said to be its residual. Standardized residuals generally have a variance of 1 . Standardized residuals with absolute value $>2$ are considered very large and treated as unusual observations. Histogram of the residuals shows distribution of residuals for all the observations. The graph of residual vs. fits should be randomly scattered about zero. One of the assumptions of regression and ANOVA is that the variance of error term is constant. In residual vs. fitted plots; these errors will have a constant variance when the residuals are scattered randomly about zero. Residual vs. order of data indicates whether there are systematic effects in data due to time or data collection order. Residual plots for the five critical responses are shown in Figure 3.

Thus, from the above PBD, it was concluded that $\mathrm{pH}$, Flow rate and Buffer ratio were the 3 most significant variables affecting all the critical responses, which were further used as critical factors for the next stage of optimization in QBD.

Selection of internal standard (IS): For internal standardization the compound selected as IS is added to the sample prior to sample pretreatment and ratio of response of analyte to that of 'IS' is plotted against concentration of the analyte. Different compounds (Aceclofenac $\mathrm{R}_{\mathrm{t}}$ 10.1; Amoxicillin $\mathrm{R}_{\mathrm{t}}$ 2.01; Brimonidine, $R_{t}$ 2.67; Flucloxacillin $R_{t} 4.08$; sulfamethoxazole $R_{t}$ 2.1; Oxcarbazepine $R_{t}-5.7$; Hydrochlorthiazide $R_{t}$ 2.23 and Carbamazepine $R_{t} 8.2$ ) were tried based on their pKa and $\log \mathrm{P}$ value. Carbamazepine was selected as IS as it showed symmetric and resolved peak from analyte (Figure 4).

Full Factorial Design (FFD) for Optimization of chromatographic Method: Based on PBD three significantly influencing factors i.e. $\mathrm{pH}, \%$ Buffer ratio and flow rate were used to get an optimized method which lead to generation of Design space in which the method is robust. Optimum ranges in which these factors were varied were confirmed from the Preliminary investigation studies (shown in Table 1). A $3^{3}$ full factorial design requiring 27 runs was employed to generate an optimized bioanalytical method. Summary of ANOVA and Fit of model are described in Table 2. Equations for all the critical responses studied are shown below:

Retention time $=+5.24-0.16 * \mathrm{~A}+1.64 * \mathrm{~B}-0.96 *$ $\mathrm{C}-0.24 * \mathrm{~A} * \mathrm{~B}+0.074 * \mathrm{~A} * \mathrm{C}-0.14 * \mathrm{~B} * \mathrm{C}+0.44 *$ $\mathrm{B}^{2}+0.11 * \mathrm{C}^{2}$

Resolution $=+5.76+0.17 * \mathrm{~A}+3.83 * \mathrm{~B}+0.088 *$ $\mathrm{C}-0.20 * \mathrm{~A} * \mathrm{~B}+0.29 * \mathrm{~A} * \mathrm{C}+0.34 * \mathrm{~B} * \mathrm{C}-0.25 *$ $\mathrm{A}^{2}+1.15 * \mathrm{~B}^{2}-0.30 * \mathrm{C}^{2}$

Asymmetry factor $\mathbf{1}=+1.20+0.076 *$ A- $0.049 *$ $\mathrm{B}+0.015 * \mathrm{C}+0.04 * \mathrm{~A} * \mathrm{~B}-0.024 * \mathrm{~A} * \mathrm{C}+0.032 *$ $\mathrm{B} * \mathrm{C}+0.031 * \mathrm{~A}^{2}-0.046 * \mathrm{~B}^{2}-0.020 * \mathrm{C}^{2}$

Asymmetry factor $2=+0.85-0.25 * \mathrm{~B}+0.090 *$ $\mathrm{C}-0.027 * \mathrm{~B} * \mathrm{C}-0.010 * \mathrm{C}^{2}+0.037 * \mathrm{~B} * \mathrm{C}^{2}$

Area $1=+1350.73+39.22 *$ A- $270.64 * \mathrm{C}$

Area $2=+1006.89+26.63 *$ A $-2.39 *$ B $-200.14 * C$ 


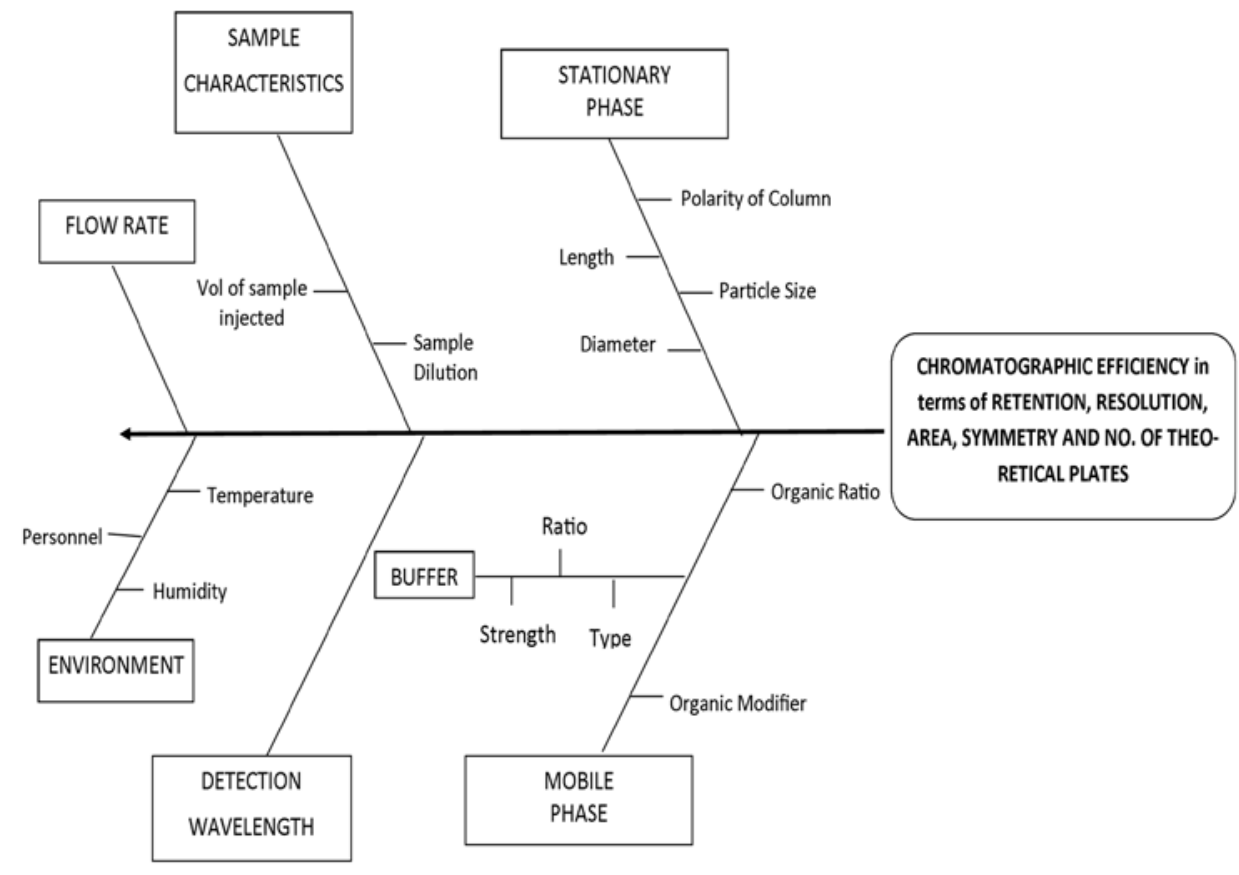

Figure 1: Ishikawa Fish bone Diagram.
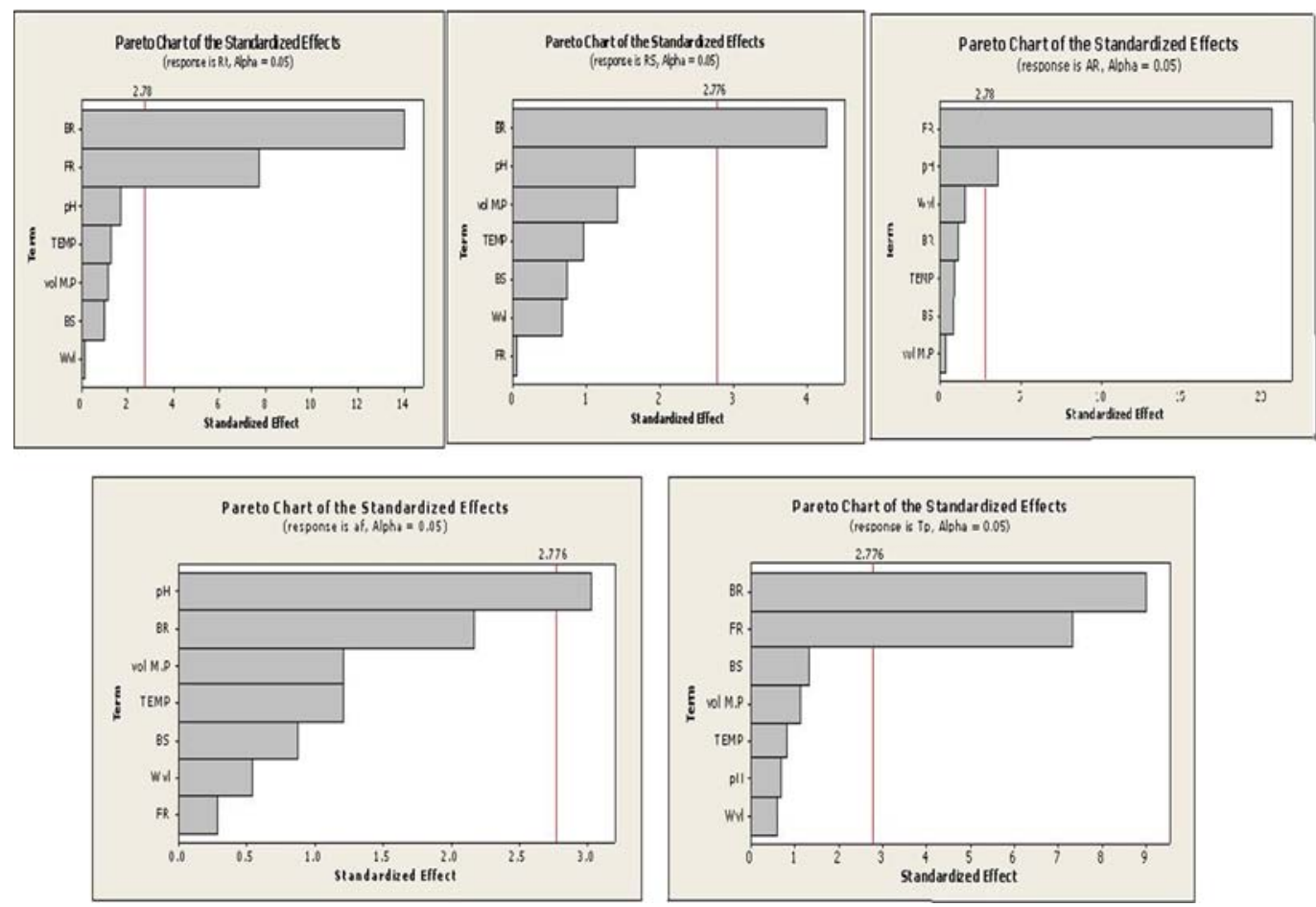

Figure 2: Pareto charts for critical responses studied (Rt =retention time, $R S=$ resolution, $A R=$ peak area, $A f=A s y m m e t r y$, $\mathrm{Tp}=$ theoretical plates). 

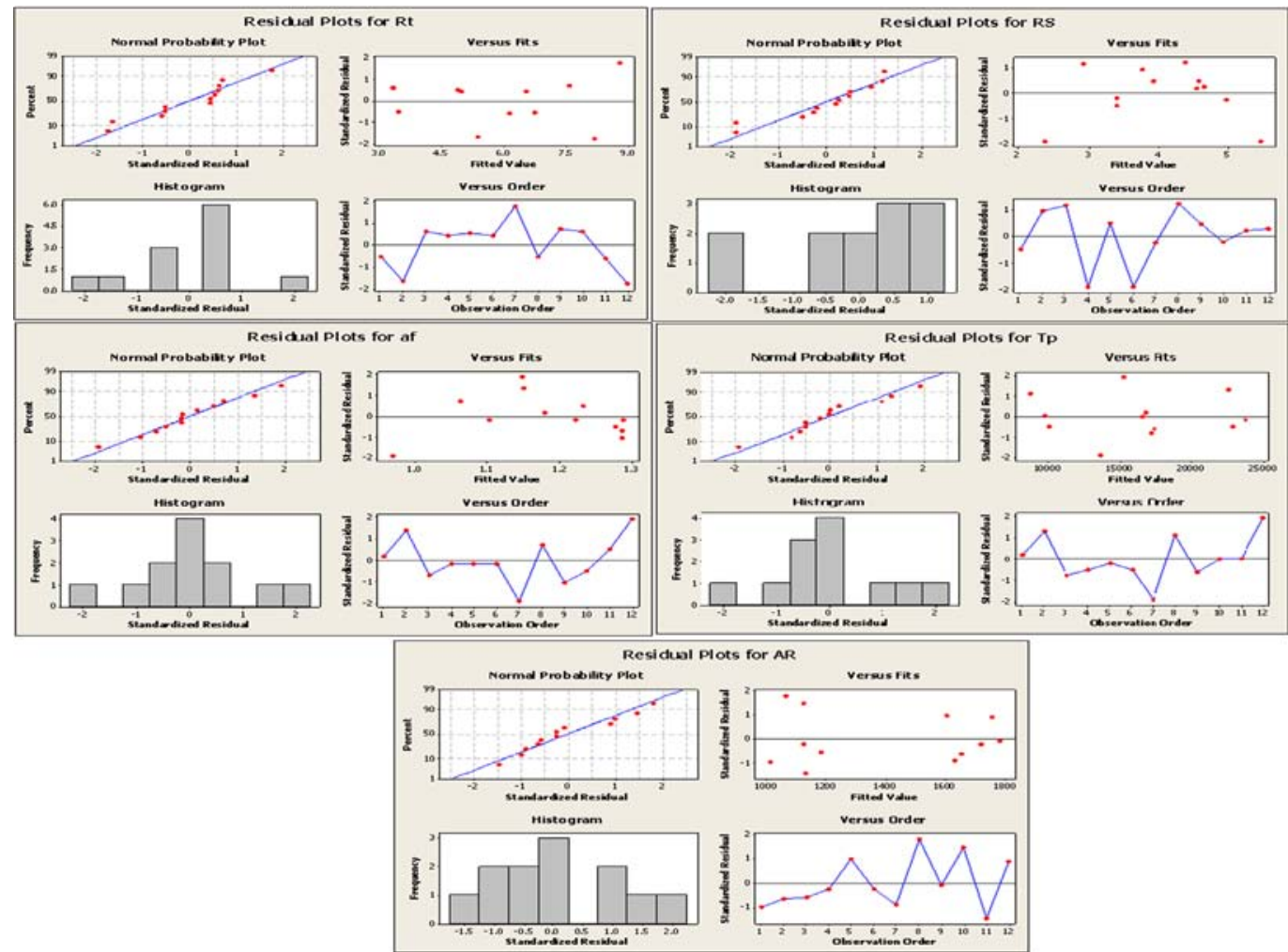

Figure 3: Residual plots for critical responses (Rt =retention time, RS=resolution, $A R=$ peak area, $A f=$ Asymmetry, $\mathrm{Tp}=$ theoretical plates).

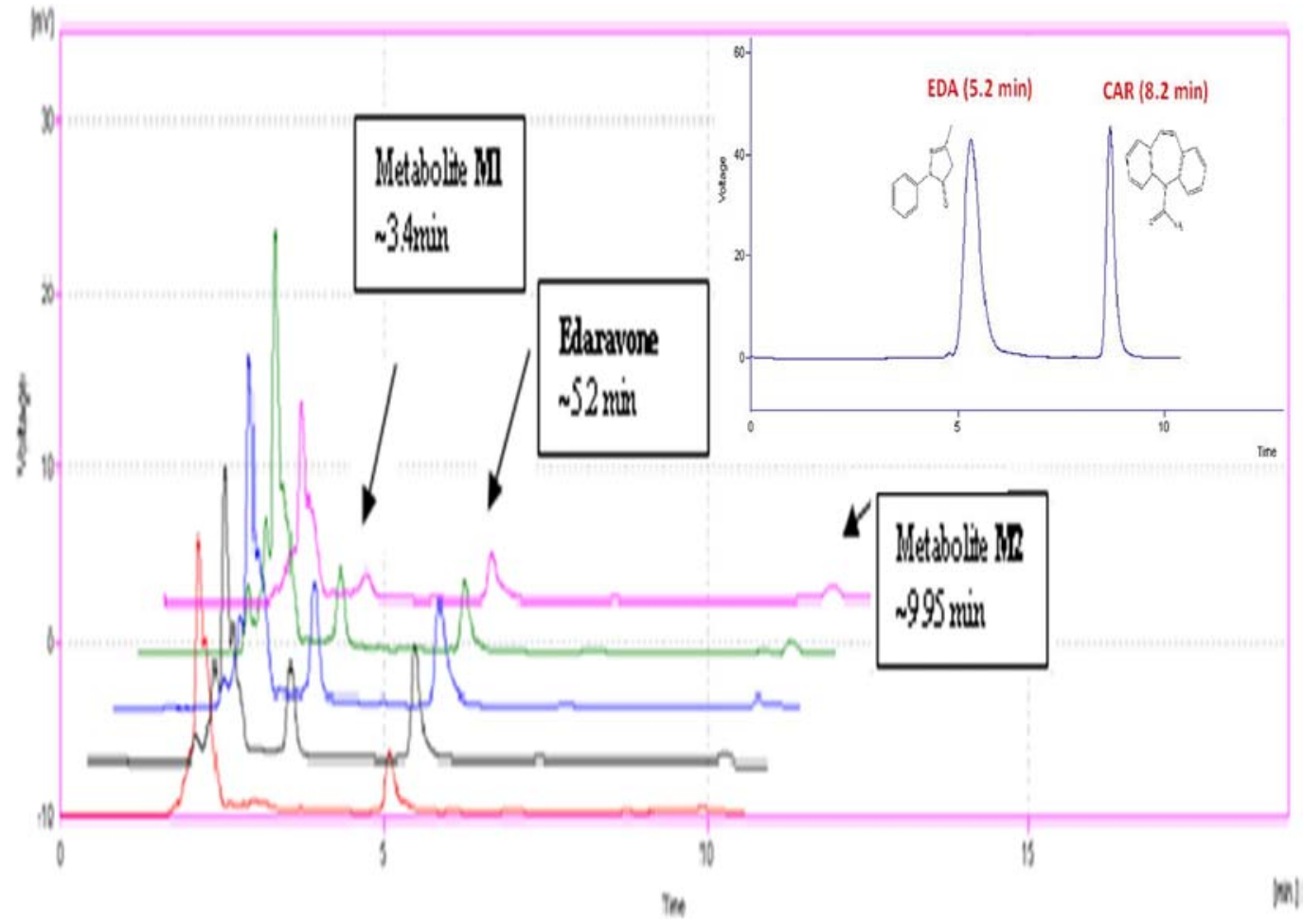

Figure 4: Chromatogram showing EDA and CAR by the optimized method and overlay chromatogram of EDA along with its metabolites in plasma at various time points. 


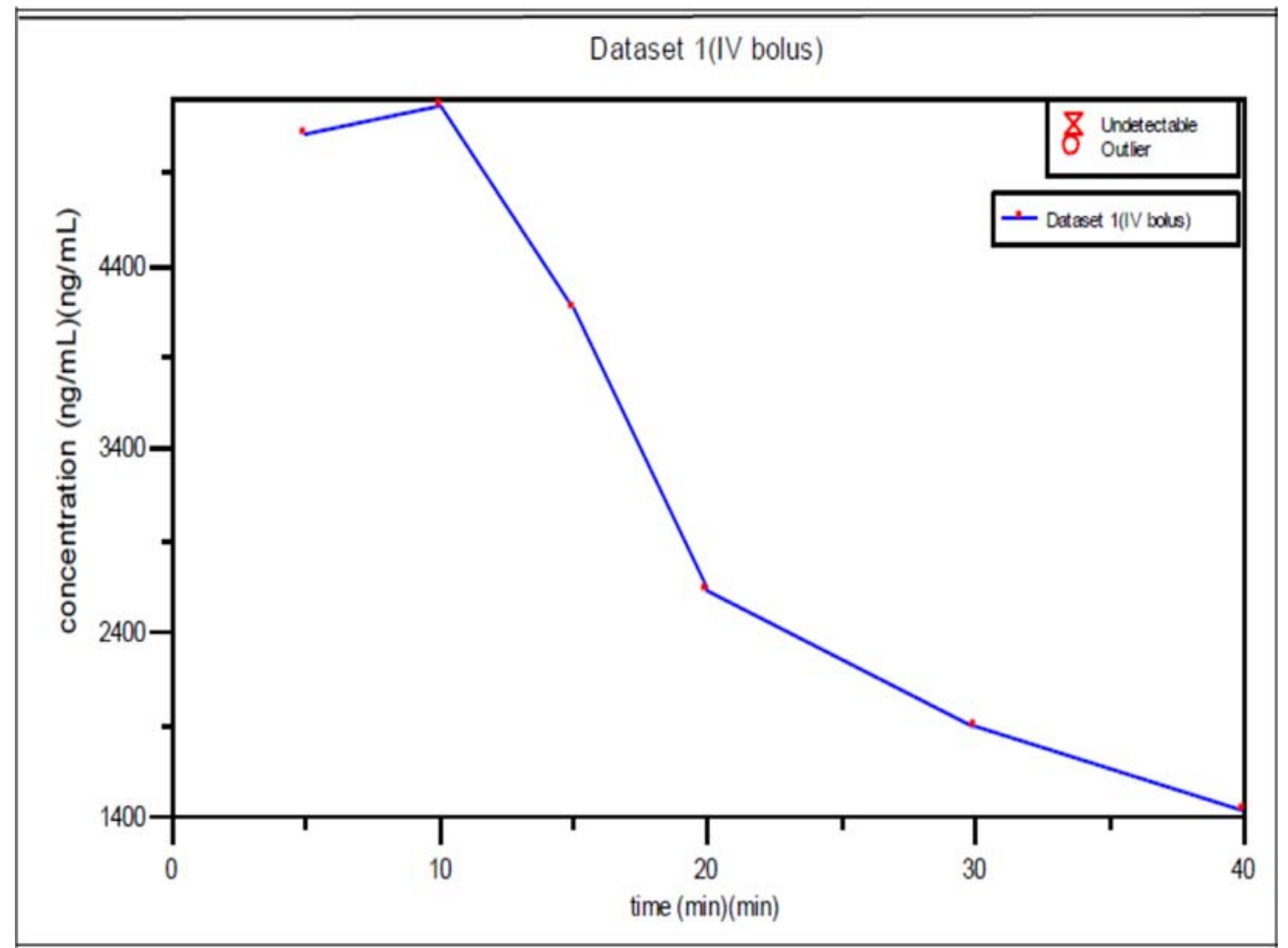

Figure 5: Mean plasma concentration vs time profile of EDA after IV administration of drug.

\begin{tabular}{|c|c|c|c|}
\hline VARIABLES & -1 & 0 & +1 \\
\hline $\mathrm{pH}$ & 5.5 & 6 & 6.5 \\
\hline Ratio of Buffer (\%) & 50 & 60 & 70 \\
\hline FLOW RATE & 0.8 & 1 & 1.2 \\
\hline \multicolumn{4}{|c|}{ RESPONSES } \\
\hline \multicolumn{4}{|c|}{ Retention time (Rt) } \\
\hline \multicolumn{4}{|c|}{ Resolution (Rs) } \\
\hline \multicolumn{4}{|c|}{ Asymmetric factor 1 (EDA) (AF1) } \\
\hline \multicolumn{4}{|c|}{ Asymmetric factor 2 (CAR) (AF2) } \\
\hline \multicolumn{4}{|c|}{ Area 1 (EDA) (AR1) } \\
\hline \multicolumn{4}{|c|}{ Area 2 (CAR) (AR2) } \\
\hline \multicolumn{4}{|c|}{ Theoretical plates 1 (EDA) (TP1) } \\
\hline \multicolumn{4}{|c|}{ Theoretical plates 2 (CAR) (TP2) } \\
\hline
\end{tabular}




\begin{tabular}{|c|c|c|c|c|c|c|c|c|c|}
\hline \multicolumn{7}{|c|}{ Table 2: ANOVA and summary of fit for full factorial model } \\
\hline Response & Stddev & $\begin{array}{c}\text { Sum of } \\
\text { squares }\end{array}$ & F-value & $\begin{array}{c}\text { P-value } \\
\text { (Prob.>F- } \\
\text { value) }\end{array}$ & R $^{2}$ & $\begin{array}{c}\text { Predicted } \\
\mathbf{r}^{2}\end{array}$ & $\begin{array}{c}\text { Adjusted } \\
\mathbf{r}^{2}\end{array}$ & AP $^{1}$ & PRESS $^{2}$ \\
\hline $\begin{array}{c}\text { Retention } \\
\text { time }\end{array}$ & 0.15 & 67.47 & 376.71 & $<0.0001$ & 0.9941 & 0.9848 & 0.9914 & 67.287 & 1.063 \\
\hline $\begin{array}{c}\text { Resolution } \\
\text { Asymmetry } \\
\text { factor 1 }\end{array}$ & 0.61 & 276.37 & 83.17 & $<0.0001$ & 0.9778 & 0.9300 & 0.9600 & 25.016 & 19.80 \\
\hline $\begin{array}{c}\text { Asymmetry } \\
\text { factor 2 }\end{array}$ & 0.11 & 1.05 & 16.23 & $<0.0001$ & 0.7944 & 0.7195 & 0.7455 & 11.185 \\
\hline $\begin{array}{c}\text { Area 1 } \\
\text { Area 2 }\end{array}$ & 70.97 & $1.346 \mathrm{E}+006$ & 133.64 & $<0.0001$ & 0.918 & 0.8980 & 0.9107 & 26.196 & 497200 \\
\hline $\begin{array}{c}\text { Theoretical } \\
\text { plates 1 }\end{array}$ & 1833.80 & $6.119 \mathrm{E}+008$ & 20.22 & $<0.0001$ & 0.9146 & 0.7712 & 0.8693 & 25.270 \\
\hline $\begin{array}{c}\text { Theoretical } \\
\text { plates 2 }\end{array}$ & 3475.37 & $1.892 \mathrm{E}+009$ & 17.41 & $<0.0001$ & 0.9021 & 0.7931 & 0.8503 & 25.270 \\
\hline
\end{tabular}

1. $\mathrm{AP}=$ Adequate Precision

2. $\mathrm{PRESS}=$ prediction error sum of squares

\begin{tabular}{|c|c|c|c|c|}
\hline QC samples & LLOQ & LQC & MQC & HQC \\
\hline $\begin{array}{c}\text { Nominal } \\
\text { Concentration(ng/ml) }\end{array}$ & $500 \mathrm{ng} / \mathrm{ml}$ & $800 \mathrm{ng} / \mathrm{ml}$ & $7500 \mathrm{ng} / \mathrm{ml}$ & $15000 \mathrm{ng} / \mathrm{ml}$ \\
\hline \multicolumn{5}{|c|}{ Intraday assay } \\
\hline $\begin{array}{c}\text { Mean obtained } \\
\text { concentration }(\mathrm{ng} / \mathrm{ml})\end{array}$ & 447.35 & 763.02 & 7660.394 & 15580.45 \\
\hline Precision (\%CV) & 3.578489 & 1.221424 & 1.791186 & 0.790739 \\
\hline \%Accuracy & 89.47 & 95.3775 & 102.1386 & 103.8697 \\
\hline \multicolumn{5}{|c|}{ Interday assay } \\
\hline $\begin{array}{c}\text { Mean obtained } \\
\text { concentration(ng/ml) }\end{array}$ & 445.3033 & 759 & 7601.048 & 15576.65 \\
\hline Precision (\%CV) & 2.744025 & 0.749603 & 1.122391 & 0.923323 \\
\hline \%Accuracy & 89.06067 & 94.875 & 101.3473 & 103.8443 \\
\hline
\end{tabular}

\begin{tabular}{|c|c|c|c|c|}
\hline \multirow{2}{*}{ Stability } & \multicolumn{2}{|c|}{ LQC (800 ng/ml) } & \multicolumn{2}{c|}{ HQC (15000 ng/ml) } \\
\cline { 2 - 5 } & $\begin{array}{c}\text { \%mean } \\
\text { stability }\end{array}$ & $\% \mathrm{CV}$ & $\begin{array}{c}\text { \%mean } \\
\text { stability }\end{array}$ & $\% \mathrm{CV}$ \\
\hline Bench top stability (24hrs) & $95.164 \%$ & 0.927 & $104.333 \%$ & 0.508 \\
\hline Freeze thaw stability (3 cycles) & $92.577 \%$ & 1.01 & $105.077 \%$ & 0.479 \\
\hline $\begin{array}{c}\text { Short term stock solution stability } \\
\text { (24 hrs) }\end{array}$ & $99.073 \%$ & 0.88 & $99.509 \%$ & 0.46 \\
\hline $\begin{array}{c}\text { Long term stock solution stability } \\
\text { (7days) }\end{array}$ & $97.243 \%$ & 1.02 & $97.862 \%$ & 0.57 \\
\hline
\end{tabular}




\begin{tabular}{|c|c|c|}
\hline \multicolumn{3}{|c|}{ Table 5: System suitability parameters } \\
\hline Parameters & Edaravone & Carbamazepine \\
\hline Retention Time & $5.25 \pm 0.08 \mathrm{~min}$ & $8.2 \pm 0.17 \mathrm{~min}$ \\
\hline Asymmetry & $1.32 \pm 0.16$ & $1.04 \pm 0.19$ \\
\hline Theoretical plate (USP) & 3464 & 9155 \\
\hline Theoretical plate/m. & 14,681 & 81,144 \\
\hline Resolution [-] & - & 5.3 \\
\hline Capacity factor & 1.76 & 3.32 \\
\hline
\end{tabular}

\begin{tabular}{|c|c|c|c|}
\hline \multicolumn{4}{|c|}{ Table 6: Pharmacokinetic Parameters } \\
\hline Parameter & $\begin{array}{c}\text { Observed } \\
\text { Value }\end{array}$ & $\begin{array}{c}\text { Reported } \\
\text { Values }\end{array}$ & Unit \\
\hline${ }^{1} \mathrm{C}_{\max }$ & 5253.38 & 5142 & $\mathrm{ng} / \mathrm{ml}$ \\
\hline${ }^{2} \mathrm{t}_{\max }$ & 10 & - & $\mathrm{min}$ \\
\hline${ }^{3} \mathrm{AUC}_{\text {total }}$ & 3011.04 & 3102 & $\mathrm{ng} / \mathrm{ml}{ }^{*} \mathrm{hr}$ \\
\hline${ }^{4} \mathrm{AUMC} \mathrm{C}_{\text {total }}$ & 1542.54 & Dose dependent & $\mathrm{ng} / \mathrm{ml}{ }^{*} \mathrm{hr} 2$ \\
\hline${ }^{5} \mathrm{t}_{1 / 2}$ & 23.3118 & - & $\mathrm{min}$ \\
\hline${ }^{6} \mathrm{MRT}$ & 0.5123 & 1.12 & $\mathrm{hr}$ \\
\hline
\end{tabular}

${ }^{3} C_{\max }:$ maximum (peak) concentration

${ }_{4}^{4}{ }_{\text {mux }}$ :time after drug administration at which peak plasma concentration occurs ${ }^{5} A U C_{\text {total }}$ area under the plasma drug concentration-time curve

${ }^{6} A U M C$ C: area under the first moment curve

${ }^{7} \boldsymbol{t}_{1 / 2}$ half-life: elimination half-life

${ }^{8}$ MRT: mean residence time

Theoretical Plates $1=+16169.81+564.94 * \mathrm{~A}-4891.33 *$ $\mathrm{B}-2334.56 * \mathrm{C}+603.08 * \mathrm{~A} * \mathrm{~B}-239.33 * \mathrm{~A} * \mathrm{C}+625.58 *$ $\mathrm{B} * \mathrm{C}-2733.28 * \mathrm{~A}^{2}+1668.89 * \mathrm{~B}^{2}+1006.56 * \mathrm{C}^{2}$

Theoretical Plates $2=+81982.48+2166.28 * \mathrm{~A}$ $-4576.72 * \mathrm{~B}-4491.06 * \mathrm{C}+1680.92 * \mathrm{~A} * \mathrm{~B}+794.42 *$ $\mathrm{A} * \mathrm{C}-4080.58 * \mathrm{~B} * \mathrm{C}+4233.39 * \mathrm{~A}^{2}+10936.72 *$ $\mathrm{B}^{2}+400.39 * \mathrm{C}^{2}$

Optimization Criteria, Point verification and working point selection: The desired target or range specified for method optimization were Retention time (5.5-6.5), Resolution (2-8), Asymmetric factor 1 and 2 (0.9-13), Area 1 and 2 (in range), Theoretical plates 1 and 2 $(>2500)$. Based on desired input goals for the responses, optimized solutions were generated by the software. Out of that 6 were selected for checkpoint analysis. All these six predictions were tested by experimental trials and the responses observed lie within 95\% confidence interval of their predicted values. One of these solutions was also selected as the final optimized working point for the proposed Bioanalytical method i.e. Ammonium Acetate buffer $\mathrm{pH}$ 6: Acetonitrile in ratio of 60:40 that gives well resolved symmetric chromatogram (Figure 4) of EDA and CAR.

Plasma Sample Preparation: Various extraction techniques were tried for sample preparation. Protein precipitation technique using methanol yielded good recovery $(70-72 \%)$, acetone yielded low recovery (about $55-57 \%$ ) and acetonitrile led to sample recovery of 78-80 $\%$. But plasma interference was relatively higher in the protein precipitation techniques. Liquid-Liquid extraction technique was tried with various extracting solvents like methyl tertiary butyl ether and diethyl ether, both yielding very low recovery (15-18\%) and ethyl acetate yielding good recovery of $68-70 \%$. Finally, solid phase extraction (SPE) technique was carried out by using various solvents like methanol, acetone, acetonitrile and various combinations of acetonitrile with acetate buffer for sample pretreatment and different brands of SPE cartridges. The best recovery (88-91\%) along with low plasma interference was obtained using mixture of acetonitrile and ammonium acetate buffer $(\mathrm{pH} 6)$ in a ratio of 80:20 on STRATA X Phenomenex SPE cartridges.

\section{Validation of developed bioanalytical method}

Assay selectivity: There was no chromatographic interference from endogenous compounds at the retention times of EDA and CAR. The chromatographic peaks were well resolved to baseline.

Limit of detection (LOD) and lower limit of quantification (LLOQ): The drug was detectable in plasma samples upto $100 \mathrm{ng} / \mathrm{ml}$ while $500 \mathrm{ng} / \mathrm{ml}$ concentration was selected as the LLOQ.

Linearity of calibration curves: The linearity of the calibration curve for EDA spiked in plasma over the concentration range of $500-20,000 \mathrm{ng} / \mathrm{ml}$ was evaluated. Calibration curves consisting of seven concentration values (500, 800, 1000, 5000, 10000, 15000 and 20,000 $\mathrm{ng} / \mathrm{ml}$ ) of EDA spiked in human plasma with respect to the area ratio of drug to internal standard were constructed. The mean linear regression equation of the calibration curves $(n=5)$ was: $\mathrm{y}=0.1075 \mathrm{x}+0.0679$; where $y$ represents the peak area ratio (EDA/CAR), and $\mathrm{x}$ represents the plasma concentration of EDA in $(\mathrm{ng} / \mathrm{ml})$. The mean correlation coefficient $\left(\mathrm{r}^{2}\right)$ was 0.994 . 
Precision and accuracy: The intraday assay $\% \mathrm{CV}$ at LLOQ, LQC, MQC and HQC were 3.578\%, 1.221\%, $1.791 \%$ and $0.791 \%$ respectively. The interday assay $\% \mathrm{CV}$ for the above concentrations were $2.744 \%$, $0.749 \%, 1.122 \%$ and $0.923 \%(\mathrm{n}=5$ in all cases) respectively. Intraday assay and interday assay accuracy ranged from $89 \%$ to $104 \%$ which is within the limits specified. The results indicate the precision, accuracy and reproducibility of the assay. These results are summarised in Table 3.

Extraction recovery: Absolute recovery of EDA and CAR was calculated which determine the extraction efficiency of method. The mean percentage extraction recoveries of EDA at the three QC concentrations (LQC, MQC and HQC) were $88.83 \%, 93.56 \%$ and $92.65 \%$ respectively. The overall $\% \mathrm{CV}$ was found to be $1.646 \%$. CAR (IS) showed relatively high extraction recovery about $94-96 \%$.

Dilution Integrity: $\% \mathrm{CV}$ for dilution integrity at $1: 2$ and $1: 4$ levels are $0.0509 \%$ and $0.962 \%$ respectively and the $\%$ mean accuracy was calculated to be $95.294 \%$ and $101.362 \%$ respectively.

Stability: EDA was stable in spiked plasma when stored for $24 \mathrm{hrs}$ at room temperature (bench top stability) and for three freeze thaw cycles at $-70 \pm 5{ }^{\circ} \mathrm{C}$ (freeze thaw stability). The stock solution of EDA was stable for $24 \mathrm{hrs}$ at room temperature (short term stock solution stability) and for 7 days at $2-8^{\circ} \mathrm{C}$ (long term stock solution stability). The \%mean stability of these samples and their $\% \mathrm{CV}$ are reported in Table 4.

System suitability tests: Parameters such as theoretical plates, asymmetry factor, capacity factor and resolution were calculated for EDA and CAR in the plasma sample solutions along with their standard deviation to determine the system suitability of HPLC method by taking six replicates of the samples. The system suitability parameters showed satisfactory results and the lower standard deviation obtained indicates the repeatability of the method. The results are shown in Table 5.

\section{Pharmacokinetic Analysis}

The proposed bioanalytical method could be applied for study of pharmacokinetics of EDA and detection of any metabolites. When the processed plasma samples collected from rats as described in section 2.8 were injected into HPLC, peak of EDA could be clearly seen at retention time of about $5.2 \mathrm{~m}$. Apart from this, two other distinguished sharp peaks could also be observed at retention times of $3.4 \mathrm{~m}$ and $9.9 \mathrm{~m}$ suggesting at least two major metabolites of EDA in plasma. Literature review revealed that these two major metabolites of EDA could possibly be Edaravone gluco-uronate and
Edaravone sulphate. Figure 4 depicts the overlay chromatograms which shows the changes in drug concentrations and metabolites of EDA at various designated time points $(5,10,15,20,30,40 \mathrm{~m})$.

The pharmacokinetic parameters were calculated with a Non-Compartmental model using Thermo Kinetica PK/PD analysis software (version 5.0 Thermo Fisher Scientific). The peak plasma concentration (Cmax) and the corresponding time $\left(\mathrm{T}_{\max }\right)$ were directly obtained from the raw data. The other pharmacokinetic parameters obtained using non compartment model is shown in Table 6. $\mathrm{AUC}_{\text {TOTAL }}$ was calculated using mixed log linear model. Concentration-time profile of EDA in rats after intravenous administration is shown in Figure 5.

\section{CONCLUSION}

QBD was not utilized in earlier reported HPTLC and LC-MS/MS methods. By adopting a QBD approach for present method, a successful model highlighting an allowed designed space for a defined response is obtained. PBD lead to filtering the highly significant critical material attributes among all the different variables affecting the process. These deduced factors when subjected to FFD generated a design space within which the method was robust. Thus, a well resolved chromatogram for Edaravone and internal standard Carbamazepine could be obtained which was then employed as a bioanalytical method. The developed assay was specific, accurate, precise and reproducible for the analysis of EDA in plasma. The use of this method can also enable the characterization of EDA pharmacokinetics after single intravenous dose without any interference of the metabolite. Compared to LC-MS, it is a simple and inexpensive method that can be easily and successfully extended to quantitate EDA in plasma for routine monitoring of levels of EDA in laboratories. However the proposed method is less sensitive as compared to reported HPTLC method.

\section{ACKNOWLEDGEMENTS}

The authors express their sincere thanks to BDR Pharmaceuticals International Pvt. Ltd., Baroda and Sun Pharmaceuticals, Vadodara for providing gift samples of Edaravone and Carbamazepine required for the study.

\section{REFERENCES}

1. Kikuchi K, Miura N, Morimoto Y, Ito T, Tancharoen S, Miyata K, et al. Beneficial effects of the free radical scavenger edaravone (radicut) in neurologic diseases. J Neurol Neurophysiol. 2011;1:1-5. http://dx.doi.org/10.4172/21559562.S1-001. 
2. Gandhimathi M, Kumar MS, Baghla R and Ravi TK. RP-HPTLC Method for the In Vitro Estimation of Edaravone in Human Plasma. Indian J Pharma Sci. 2010;72(2):276-82.

3. Ping L, Zheng-Yu Y, Zhi-Ji X and Xiao S. A novel fluorescent assay for edaravone with aqueous functional CdSe quantum dots. Spectrochemica Acta Part A: Mol. and Biomol. Spectro. 2009;72(5):75.

4. Patel B, Raj $\mathrm{H}$ and Jain V. Simultaneous estimation of edaravone and citicoline sodium by ratio derivative spectroscopic method in synthetic mixture. Pharma Science Monitor 2014; 5(2):118-28.

5. Patel B, Raj H, Jain V, Sutariya $\mathrm{V}$, Bhatt $\mathrm{M}$, et al. Method development and validation of RP-HPLC for simultaneous estimation of edaravone and citicoline sodium in synthetic mixture. Invent rapid J Pharm analysis and Quality assurance. 2014;4:3.

6. Li jin-lin. Determination of Phenyl hydrazine Residues in Edaravone by HPLC. J China Pharmacy. 2008;31:2454-5.
7. Dao-quan Tang. LC-MS/MS methods for the determination of Edaravone and/or taurine in rat plasma and its application to a pharmacokinetic study. Biomed. Chromatogr. 2014;28(9):1173-82. http://dx.doi.org/10.1002/ bmc.3139; PMid:24706508.

8. F.D.A., 2003. Guidance for Industry: Bioanalytical method validation, U.S. Department of Health and Human Services, Food and Drug Administration, Center for Drug Evaluation and Research (CDER) and Center for Veterinary Medicine.

9. $\mathrm{ICH}$ Q8 (R2) 2009. International Conference on Harmonization (ICH) of Technical Requirements for Registration of Pharmaceuticals for Human Use, Topic Q8 (R2): Pharmaceutical development.

10. ICH Q9 2009. International Conference on Harmonization $(\mathrm{ICH})$ of Technical Requirements for Registration of Pharmaceuticals for Human Use, Quality Risk Management.

\section{SUMMARY}

- SPE-HPLC bioanalytical method of Edaravone, a neuroleptic drug indicated in treatment of acute ischemic stroke, has been developed and utilized for pharmacokinetic study and determination of it's metabolites in rat plasma. The method was developed by utilizing principles of quality by design. Placket burman design with seven variables was used for screening, and full factorial design with three variables was used for optimization of chromatographic condition. Carbamazepine was used as internal standard and the method was validated as per USFDA guideline. The mobile phase of optimized method comprised of ammonium acetate buffer $(10 \mathrm{mmol}, \mathrm{pH} 6)$ and acetonitrile in the ratio of $60: 40 \mathrm{v} / \mathrm{v}$. The separation was carried out on Kromasil RP C-18 column ( $250 \mathrm{~mm} \times 4.6 \mathrm{~mm} ; 5 \mu \mathrm{m}$ ) at wavelength of $243 \mathrm{nmat}$ flow rate of $1 \mathrm{ml} / \mathrm{min}$. Solid phase extraction using STRATA X C18 Phenomenex cartridges was utilized for extraction of Edaravone and internal standard from biological matrix. The retention time of Edaravone and carmazepine were 5.2 and 8.2 min respectively, while two metabolites were observed at retention time of 3.4 and $9.9 \mathrm{~min}$.

\section{About Authors}

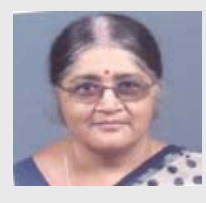

Sadhana Rajput: Quality Assurance Laboratory, Centre of Relevance and Excellence in Novel Drug Delivery System, Pharmacy Department, G. H. Patel Building, Donor's Plaza, The Maharaja Sayajirao University of Baroda, Fatehgunj, Vadodara, Gujarat, INDIA. 